\title{
Medical mineralogy as a new challenge to the geologist: Silicates in human mammary tissue?
}

\author{
Jill Dill PASteris, ${ }^{1} *$ BrigitTe Wopenka, ${ }^{1}$ John J. Freeman, ${ }^{1}$ V. Leroy Young, ${ }^{2}$ AND \\ HAROLD J. BRANDON ${ }^{2,3}$
}

\author{
${ }^{1}$ Department of Earth and Planetary Sciences, Washington University, Campus Box 1169, St. Louis, Missouri 63130-4899, U.S.A. \\ ${ }^{2}$ Washington University School of Medicine, Division of Plastic Surgery, 1040 North Mason Road, Suite 206, \\ St. Louis, Missouri 63141-6366, U.S.A. \\ ${ }^{3}$ Department of Mechanical Engineering, Washington University, Campus Box 1185, St. Louis, Missouri 63130-4899, U.S.A.
}

\begin{abstract}
Medical questions surrounding the toxicity of "silica" and other silicon-containing materials introduced into the body can be answered only through use of microanalytical techniques that provide chemical and structural analyses of microscopic and submicroscopic particles. A useful approach to the study of minerals and other foreign substances associated with silicone breast implants is to use polarized-light optical microscopy to pinpoint the materials of interest in the tissue and to follow that observation with analysis by Raman spectroscopy. Silicone breast implants contain both the organic polymer silicone and particles of amorphous silica. We studied the breast tissue from six women who had silicone breast implants and from three controls who never had implants to address questions about post-implant alteration, such as to "crystalline $\mathrm{SiO}_{2}$." Optical analysis of the mammary tissue sections revealed a variety of birefringent and non-birefringent, non-cellular materials. Raman spectroscopic analyses of those substances identified many similar materials in tissue from women with and without silicone implants: calcite, apatite, starch, lipid, and $\beta$-carotene. We also spectroscopically identified silicone (only in breast tissue from patients recognized to have had ruptured implants) and paraffin (only in one sample that had been embedded in paraffin and subsequently "deparaffinized"). In tissue sections of $5 \mu \mathrm{m}$ thickness (standard thickness of pathology sections), it is impossible to detect optically the birefringence of quartz (or any other form of crystalline $\mathrm{SiO}_{2}$ ), even though it may be possible to image such thin crystalline $\mathrm{SiO}_{2}$ grains in polarized light due to light-scattering phenomena. Moreover, neither crystalline nor amorphous silica was identified by Raman spectroscopy in the tissue sections. Review of the pathology literature on such materialsbased issues as silicosis and calcification revealed some misapplication of the optical microscopy term "birefringence" and misleading identifications of minerals in tissue sections. Our conclusion is that useful collaborations can be developed between (1) pathologists who observe foreign materials in tissue sections and understand the medical context of their findings and (2) mineralogists who routinely use optical, chemical, and structural analyses to characterize micrometer-sized crystalline materials and who understand materials properties.
\end{abstract}

\section{INTRODUCTION}

The current project illustrates some of the challenges faced by both pathologists and mineralogists who attempt to identify and to understand the occurrence of non-cellular materials in human tissue. Some of those materials are indigenous crystalline solids, or "biominerals." The latter are biologically precipitated phases that, except for their biological genesis, would be called minerals, e.g., apatite in bone and weddellite in kidney stones. In addition, due to increasing concern about the health effects of inhaled particles (e.g., Guthrie and Mossman 1993; Goldsmith 1994; Hardy and Weill 1995; Beckett 1997; Murphy

*E-mail: pasteris@levee.wustl.edu et al. 1998) and to the widespread medical and cosmetic use of prosthetic devices and other implants, pathologists now are also called upon to recognize foreign materials within human tissue, including the products of interactions between tissue and inhaled particles or implants (e.g., BéruBé et al. 1998). Two questions are discussed here. (1) What are the compositions and structures of the non-cellular materials that are found in human tissue? This is more a mineralogic and materials-science issue than a medical one. (2) Why are certain crystalline materials found in human tissue? This is a biological and medical issue, but materials and earth scientists can provide helpful insights based on their knowledge of the stability, solubility, and precipitation of natural inorganic crystalline materials (e.g., Skinner et al. 1988; Guthrie 1992; Guthrie and Mossman 1993; Werner et al. 1995; Poggi et al. 1998). 
Our mineralogic interest in the medical field was initiated by repeated reports in the pathology literature about the finding of "crystalline silica" in mammary tissue of women who had silicone breast implants and the claim that such crystalline silica had originated from the materials used in the implants (Shanklin 1991; Shanklin and Smalley 1995; Shanklin and Smalley 1996a, 1996b, 1996c; Smalley and Shanklin 1997). In defense of their conclusions about the presence of silica in breast tissue, Shanklin and Smalley (see above) relied on well accepted, but mineralogically misleading, statements in the pathology literature concerning the optical detection of crystalline and amorphous silica in lung tissue of patients diagnosed with silicosis (e.g., Craighead 1988; McDonald and Roggli 1995).

\section{Silica and silicone: Materials issues}

The medical and mineralogic communities have crossed paths a number of times in the past two decades due to mutual interests in Si-bearing phases, such as "asbestos" (asbestosis) and "silica" (silicosis)—admittedly not the terminology that mineralogists would choose (e.g., Skinner et al. 1988; Guthrie and Mossman 1993). These medical concerns about the health effects of exposure to minerals have led to not only an increased public interest in silicates, but also a public misconception about silicates. Anxiety about silicosis has led government agencies to view $\mathrm{SiO}_{2}$ as a health hazard (Goldsmith 1994; Hardy and Weill 1995; Beckett 1997), thus establishing a backdrop for concern about "silicates" in the body. The extensive use of silicone implants and other medical devices in the body (as in medical shunts, heart valve poppets, eye implants, insulation for pacemaker leads, tubing in dialysis pumps, interactive wound dressings, and the controversial breast implants) and the discussion about their safety (e.g., Vondráček and Doležel 1984; Sturrock 1998) have brought further attention to Si-bearing compounds.

The specific materials science issue that we address in the present study is the contention that crystalline $\mathrm{SiO}_{2}$ occurs in the breast tissue of women who were exposed to silicone implants. Researchers who support this notion have suggested that either the amorphous silica within an elastomer shell can be released into the body and can transform into crystalline silica or silicone gel can "autoconvert" to silica (Peters 1995; Shanklin and Smalley 1996b).

Silicones are organic, synthetic polymers containing a backbone of repeating $\mathrm{O}$ and $\mathrm{Si}$ atoms. Different organic groups attached as side groups on the $\mathrm{Si}$ atoms provide for a variety of different types of silicones, whereas variations in chain length and degree of cross-linking between chains can vary the physical properties of a particular silicone from those of a liquid to a viscous gel to a stiff elastomer. As this brief description indicates, there are many analogies between silicones and silicate minerals and melts (e.g., variable degrees of polymerization, effect of polymerization on viscosity). One of the best-known silicones, due to its use in the gels and enclosing elastomer shells of silicone breast implants, is polydimethylsiloxane (PDMS), in which methyl $\left(-\mathrm{CH}_{3}\right)$ groups are attached to the $\mathrm{Si}$ atoms (Fig. 1). In silicone elastomers, amorphous ("fumed") silica, which has been treated with a surface agent to make it

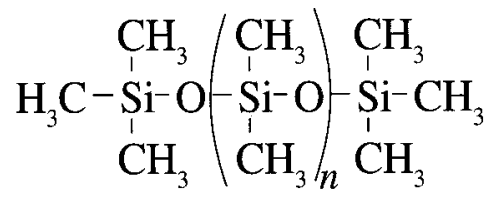

Polydimethylsiloxane (PDMS)

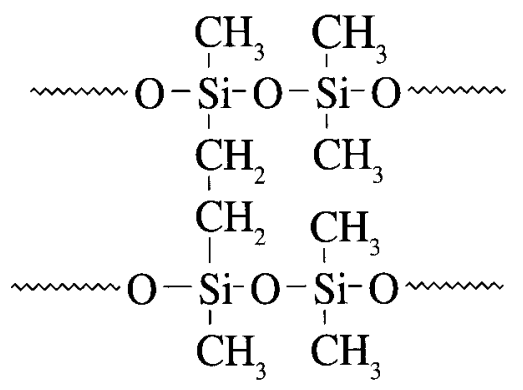

Cross-linked Polydimethylsiloxane

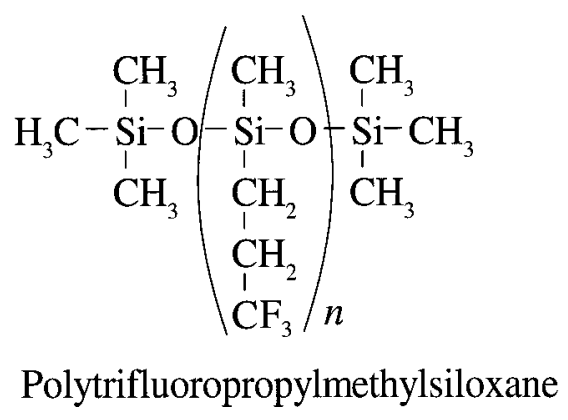

FiguRE 1. Chemical-structural formulae of the major components used in silicone elastomer shells of silicone breast implants. See text for details.

hydrophobic and compatible with a silicone matrix, is added to PDMS as a reinforcing agent to increase the tensile strength of the elastomer. A tenfold increase in the tear-resistance properties of the elastomer occurs through interactions between the fumed silica, with its enormous surface area (approximately $400 \mathrm{~m}^{2} / \mathrm{g}$; Cabot Corporation product information), and the host silicone (Rochow 1987; Smith 1991; Michael and Ferch 1993).

The term "amorphous" is used similarly in industry and in mineralogic fields, as a descriptive term that indicates the lack of crystallinity of the silica, but with no connotation of how the silica was produced. In contrast, the industrial terms "fumed" and "precipitated" refer to the process by which the amorphous silica was produced, whereas the term "colloidal" indicates the intended end-use of the amorphous product (Iler 1979; Michael and Ferch 1993). Fumed silica is the product of high-temperature hydrous pyrolysis of $\mathrm{SiCl}_{4}$ (no crystalline material present), which condenses so rapidly that it forms amorphous particles several to several hundred nanometers in diameter that may cluster into larger aggregates (Iler 1979; Michael and Ferch 1993). 
Breast implants are essentially fluid-filled bags. Typical silicone gel breast implants consist of two or three silicone-based materials. A low-viscosity PDMS gel with relatively little crosslinking fills the implant and thus is the major component of the device. The gel is enclosed in a highly viscous, tough elastomer shell on the order of several tenths of a millimeter thick, consisting of a strongly cross-linked (Fig. 1) copolymer of dimethylsiloxane (dominant) and methylvinylsiloxane reinforced with up to $\sim 25 \mathrm{wt} \%$ fumed amorphous silica. The aggregated clumps of silica within the elastomer shell typically are on the order of $150 \AA$ to several thousand angstroms in diameter (Smith 1991; Michael and Ferch 1993; Picard et al. 1997; J. Freeman, unpubl. data). The inside face of the shell (in contact with the gel) also may be coated with a 5 to $50 \mu \mathrm{m}$ thick layer of polytrifluoropropylmethylsiloxane (Fig. 1), a fluorosilicone compound that is added to deter the outward diffusion of short-chain silicones from the gel through the shell and into the body (Smith 1991; Picard et al. 1997). There are a number of variations on the above-described implants, but this summary is sufficient to indicate the nature of the raw materials that are introduced into the tissue by an implant. Approximately two million women in North America had such devices implanted up to 1992, when the FDA prohibited additional implantations for cosmetic purposes pending further health and safety studies (Noone 1997). Another common type of breast implant, which is unaffected by the above ban, consists of a saline aqueous fluid in a silicone shell.

In terms of human tissue, the materials of interest in this paper are not the major components of breast tissue (proteins and lipids), but rather objects ranging from 1 to $>10 \mu \mathrm{m}$ in diameter that can be either crystalline solids (grains, euhedral crystals), amorphous masses, or liquids. Those materials can be naturally occurring in healthy human tissue (e.g., crystals of calcite and apatite) or be non-inherent to normal breast tissue (e.g., silicone globules). Non-inherent materials found in breast tissue could have come directly from breast prostheses or their breakdown products (silicone gel, silicone elastomer, amorphous silica), grown in place as the product of a biological response to the implant, or been introduced artificially during the course of surgery or subsequent handling of the tissue (e.g., suture materials and powders from the latex gloves of the surgeon and technician).

Of interest in breast-implant medicine is a particular kind of tissue that forms around a silicone breast implant and that is in direct contact with the implant. This scar-like tissue, called "capsular tissue," can be up to several millimeters in thickness. It is rich in collagen and can become very fibrous and inelastic. (Such capsules form in response to silicone implants of any type that are placed into soft tissue.) Surgical removal (explantation) of implants that have ruptured, followed by analysis of the surrounding tissue, shows that most of the released silicone gel has been retained within this capsular structure, although small quantities can migrate, especially into lymph nodes (Barnard et al. 1997). In numerous cases, macroscopic and microscopic observations of surgically explanted material have revealed solid phases, typically phosphates (especially calcium phosphates), on the surface of the capsular tissue that faces the silicone implant (e.g., Rolland et al. 1991). The materials is- sues surrounding silicone breast implants therefore involve the detection and identification in human breast tissue of (1) Sibearing compounds that are either chemically altered or unaltered products of silicone implants and (2) crystalline reaction products related to silicone implants.

\section{Silica and silicone: Microscopy issues}

Pathologists typically view stained, covered sections of tissue that are 4-6 $\mu \mathrm{m}$ thick under Köhler configuration for illumination using a transmitted-light microscope outfitted for polarization. In general, attention is focused on the cellular portions of the tissue sections, which reveal anomalous growth and morphology. It is in part the low relief among various portions of tissue that has led to the standard use of stains, which both enhance internal optical contrasts and selectively tag specific cellular components. Non-cellular materials commonly are distinguished by their inability to be stained and because they are "refractile," meaning that they show optical relief with respect to the surrounding tissue. The application of polarizedlight microscopy allows the additional distinction to be made between so-called "polarizable" and "non-polarizable" materials. Among the recognized birefringent materials in tissue sections are such non-crystalline substances as anisotropic tissue (e.g., collagen) and suture materials. In many cases, however, the term "birefringent" is equated with "crystalline," and foreign materials that appear polygonal in outline may be called "crystalline" even when they are known to be synthetic elastomers (Kasper 1994; Kasper and Chandler 1994).

One of the most significant misuses of polarized-light, optical microscopy terms, which is found in the silicone breast implant literature and in the silicosis literature, is the blurring of the distinction between birefringence and simple visibility under crossed polarizers (to which we apply the term "visualize" or "visualization"). Thus, the term birefringent is applied incorrectly to everything that looks "bright" under crossed polarizers (Craighead 1988). Various optical effects, however, can be noted under crossed polarizers, some of which are much less useful than others as a diagnostic criterion (Chamot and Mason 1958). For instance, the light-scattering off of multiple grain boundaries, as occurs in aggregations of submicrometer (even optically isotropic) grains, can produce a hazy whiteness under crossed polarizers. For much the same reason, a single small (less than a few micrometers in diameter) isotropic grain can appear quite bright under crossed polarizers if it has sufficient optical relief with respect to its matrix; these "edge effects" from light-scattering dominate the appearance of small grains. Such rotations of the plane of polarization that are simply due to scattering appear to have been confused with true birefringence in some of the medical literature (e.g., Craighead 1988; McDonald and Roggli 1995; touched upon in discussions of "form birefringence" by Wolman 1970, 1975).

Among the misstatements concerning birefringence in the histopathology literature is the statement that "polarized light microscopy of various tissues from silicone breast implant patients often shows birefringent crystals that are morphologically consistent with crystalline silica and identical to those seen in occupational silicotic tissues..." (Smalley and Shanklin 1997, p. 1730). First, the optical properties of quartz were mis- 
represented by them. The $5 \mu \mathrm{m}$ thickness of pathology sections permits visualization under crossed polarizers of only the most strongly birefringent materials. Neither quartz (a known culprit in silicosis and a phase reported in conjunction with silicone implants) nor apatite (a mineral very similar to bone and a phase implicated in several types of pathologic calcifications) can be recognized by its birefringence in standard pathology tissue sections, which, as noted above, have a thickness of $\sim 5 \mu \mathrm{m}$ in contrast to $\sim 30 \mu \mathrm{m}$ for standard petrographic sections. This limitation of quartz is not widely acknowledged in the pathology literature, in part due to lack of understanding of mineral optics and in part due to the confusion between the observations of true birefringence and simple light scattering, as discussed earlier. Second, if the above quotation instead refers to observations of brightness that are not due to birefringence, then there is a different problem: the quotation's reference to silicotic tissue improperly suggests that non-specific, light-scattering phenomena can be used to specify the phase that is present.

The above points lead to two conclusions. First, quartz has not been identified by optical microscopy in breast tissue examined in standard pathology sections. This statement does not rule out the possibility that amorphous silica or quartz (neither of which shows observable birefringence in standard tissue sections) occurs in such tissue, but rather only reflects the inability of optical microscopy to provide support for such identification. Second, particles that appear "bright" under crossed polarizers in tissue sections may be either inherently birefringent or non-birefringent materials that require more than optical microscopy for their definitive analysis.

\section{TISSUE SAMPLES AND ANALYTICAL METHODS}

In this study, we looked at 30 sections of breast tissue from eight different women (Table 1), three that had undergone breast-reduction surgery (with no present or prior implants) and five whose silicone breast implants had been removed. The samples were selected to provide tissue representative of a wide range of patient types. As indicated in the table, among the six explants, two of the silicone implants had ruptured prior to explantation; three patients reported health problems. The tissue from the reduction patients (never had implants) establishes the baseline mineralogy of breast tissue that has been surgically removed and prepared for sectioning. From the above explant patients, we studied capsular tissue in thin section. A ninth sample (patient no. 9, Table 1) was mineral powder removed from the surface of macroscopically mineral-coated capsular breast tissue, termed "capsular calcification" pathologically.

Immediately after surgery, the breast tissue was frozen and stored at $-80{ }^{\circ} \mathrm{C}$. The tissue remained frozen at temperatures not exceeding $-20{ }^{\circ} \mathrm{C}$ until it was imbedded in OCT (i.e., a polyvinyl alcohol-polyethylene glycol solution). The tissue was cut to the desired thickness using a cryostat, and affixed to a glass slide using poly-L-Lysine as the tissue adhesive. The sections were treated as standard pathology sections except that they were not fixed in formalin, embedded in paraffin, stained, or placed under cover glasses, and that they were cut to either 10 or $20 \mu \mathrm{m}$ thickness.
TABLE 1. Patients whose breast tissue was studied by polarizedlight optical microscopy and Raman spectroscopy

\begin{tabular}{cl}
\hline \hline Patient no. & \multicolumn{1}{c}{ Silicone gel breast implant history } \\
\hline 1 & no implant; breast reduction \\
2 & no implant; breast reduction \\
3 & no implant; breast reduction \\
4 & $\begin{array}{l}\text { silicone-gel implant explanted after } 9 \text { years; } \\
\text { implant ruptured; patient was symptomatic }\end{array}$ \\
5 & $\begin{array}{l}\text { silicone-gel implant explanted after 21 years; } \\
\text { implant ruptured; patient was asymptomatic }\end{array}$ \\
& silicone-gel implant explanted after 11 years; \\
6 & implant was intact; patient was symptomatic \\
7 & silicone-gel implant explanted after 10 years; \\
& implant was intact; patient was symptomatic \\
8 & silicone-gel implant explanted after 10 years; \\
& implant intact; patient was asymptomatic \\
9 & silicone-gel implant explanted after 21 years \\
\hline
\end{tabular}

The section-making technique (above) that was used for our sample preparation is a slight variation on standard cryogenic sectioning technique. We relied on experience with geological thin sections in considering how the tissue-section-making process should be optimized for preservation of and microscopic visualization of crystalline and other non-cellular materials within human tissue sections. The extreme difference in hardness and ductility between tissue and crystalline materials calls for special preparation of the tissue sample for cutting and careful selection of the cutting blade. Our concern is that materials distinctly harder or more viscous than their matrix could be selectively plucked out during cutting. Of the two typical methods of tissue preparation, i.e., imbedding of room-temperature tissue in paraffin (predominant technique) and freezing of tissue to between $-20 \%$ and $-80{ }^{\circ} \mathrm{C}$, we strongly recommend the latter. The cryogenic technique produces a harder tissue block with more homogeneous hardness properties than those of room-temperature tissue embedded in and impregnated with crystalline paraffin. The reduction in hardness differences between those two components in the block should lessen the "drop-out" or plucking of phases that do not adhere firmly to their matrix, e.g., silicone gel in vacuoles. For study of noncellular phases, the tissue sections should be cut thicker (20$30 \mu \mathrm{m}$ ) to allow thicker grains (if they occur) to be visualized and to aid in the optical testing and identification of such grains. Thicker sections also would increase the sampling volume that is viewed in an individual section and would lessen the selective plucking of materials whose physical properties contrast with those of the matrix (Raso et al. 1994; Raso and Greene 1997).

As with all techniques, it is important to consider artifacts of processing and analysis. In the tissue-sectioning technique that we used, the tissue can become desiccated due to the lack of a cover glass. Such desiccation can change the birefringence of the tissue, especially collagen. The extreme cooling of the tissue enhances the crystallization of lipid, which could interfere with the search for foreign crystalline phases (Wolman 1975; Wolman and Kasten 1986).

The sections were viewed in transmitted light with an Olympus BH-2 optical microscope, outfitted for geological/ 
materials science research (e.g., rotating stage, polarizer and analyzer, strain-free objectives). Both Köhler and non-Köhler modes of illumination were used while viewing the sections in either plane-polarized (P-P) light or cross-polarized (X-N) light. Most viewing was done in transmitted light, but vertically incident reflected light was used in some instances. We used objectives up to $160 \times$ magnification and $10 \times$ oculars. The samples were photographed using Kodak TMAX 100-ASA, black-andwhite film from which high-contrast glossy photographs were produced.

Optical microscopy permitted the observation of a variety of micrometer-sized phases that distinguish themselves from the unstained tissue by contrasts in refractive index and/or by birefringence. Such phases account for less than $1 \mathrm{vol} \%$ of the section. Both the minute size of the phases and the lack of multiple examples (and grain orientations) of them, however, preclude their unambiguous identification by optical microscopy alone. Microscopic observation therefore was followed by laser Raman microprobe spectroscopy. The latter provides a pinpoint (1-2 $\mu \mathrm{m}$ in diameter) vibrational spectroscopic analysis of the specific volume that is being imaged with the microscope.

Raman microprobe analyses were done (for the most part) non-destructively with a Jobin-Yvon model S3000, triple-monochromator, laser Raman microprobe using the $514.5 \mathrm{~nm}$ green line of an argon-ion laser and about $10 \mathrm{~mW}$ power at the sample surface. The instrument configuration and operating conditions are described in Pasteris and Chou (1998). Analyses were done using an $80 \times$ ultra-long-working-distance objective with a numerical aperture of 0.75 . The analysis of a grain in situ in a tissue section typically took only several minutes. The main requirements for such analyses are that the tissue section be unstained (typical hematoxylin and eosin stain used in tissue sections induces unwanted fluorescence) and that a cover glass not be used. The laser power also must be adjusted to avoid burning the tissue.

\section{RESULTS}

In response to the recent published reports of birefringent materials and the suggested possible occurrence of crystalline $\mathrm{SiO}_{2}$ in breast tissue (e.g., Shanklin and Smalley 1996a, 1996b; Smalley and Shanklin 1997), we focused particular attention on the analysis of materials that are visibly bright in tissue sections observed under crossed polarizers. Some birefringent substances clearly are part of normal tissue, such as the fibrous protein collagen, which is abundant in the explanted capsular tissue (Fig. 2a). Crystalline precipitates from fluids (lipids) also may show birefringence (Fig. 2b). Such precipitates, which may occur in obvious globules of fluid, commonly consist of bundles or clusters of elongated crystals. Under crossed polarizers, only the core of the cluster, where all the elongated crystals overlap, may be bright. The individual elongated crystals typically are too thin to show birefringence. Raman microprobe analysis of naturally occurring components of human tissue (Fig. 3) produced spectra of protein, $\beta$-carotene, cholesterol, and lipid (such as the crystalline lipid cluster described above; Figs. $2 b$ and $3 b)$.

The items of greatest interest in this study, however, were the non-cellular birefringent materials. One of the most common non-cellular birefringent materials found in both implant and reduction patients appears as round, high-relief inclusions a few micrometers in diameter that show a Maltese cross under crossed polarizers, indicative of spherulitic growth of needlelike crystals (Fig. 2c). Insertion of a first-order compensator plate shows the individual needles to be length-fast. When such pancake-like grains are rotated on edge and sectioned at a random angle, the Maltese cross is not observed. Without additional microanalysis, such artifacts could be misidentified as strongly birefringent crystalline mineral grains, such as talc. In the tissue sections that we studied, however, all the spherulitic granules demonstrating Maltese-cross phenomena were identified via Raman spectroscopy as starch (Fig. 3h). These grains (Fig. 2c) most likely were derived from the powdered gloves worn during surgery or during preparation of the tissue section (confirmed by our optical microscopy and Raman spectroscopy of particles on the surface of several types of modern surgical gloves). Raman spectroscopy proved very useful in distinguishing and identifying these phases because the spectra of starch and talc are distinctive (Figs. $3 g$ and $3 \mathrm{~h}$ ).

Two other strongly birefringent, and thus highly visible, materials on the order of several micrometers in length were common in the limited number of tissue sections studied in this work. In explant patients, we observed shreds of highly anisotropic fibers that in many cases showed feathery extinction along their edges. Such fibers were very heat-sensitive and usually burned rapidly under the laser beam, precluding Raman analysis. Our interpretation is that these are either suture fragments from earlier surgery or cellulose (as from Kimwipes). Another possible artifact, which is introduced during paraffinembedding, is highly birefringent crystals of paraffin. Paraffin impregnation and embedding are the most commonly used means of preparing tissue samples for sectioning; many residual tissue samples are simply stored in their enclosing paraffin blocks. There is a long-standing method for the dissolution of the paraffin once the tissue is sectioned and affixed to a glass slide. We studied tissue from implant patient no. 9 (Table 1) that was supposed to be "deparaffinized" after its original paraffin impregnation. However, we observed strongly birefringent crystals in the tissue that show the Raman spectrum for paraffin (Fig. 3d). Potentially, such birefringent paraffin grains, particularly if they are small and polyhedral, could be misinterpreted as mineral grains. We therefore suggest the avoidance of paraffin preparation techniques if the non-cellular materials in the tissue are the focus of investigation.

Some materials in the sections clearly appeared to have been generated by the tissue. There are polygonal particles on the order of 1-2 $\mu \mathrm{m}$ in diameter and probably not much greater in thickness, which we observed in tissues from both explant and reduction patients. These grains are distinguished in plane-polarized light by their high relief and under crossed polarizers by their strong, white, even illumination, which indicates a very high birefringence. Raman analyses of more than a dozen such grains identified them as calcite (Fig. 3c), whose spectrum is distinguishable from that of aragonite (which was not found). We also performed Raman analyses on material scraped from complete, unsectioned portions of the capsular tissue from one 

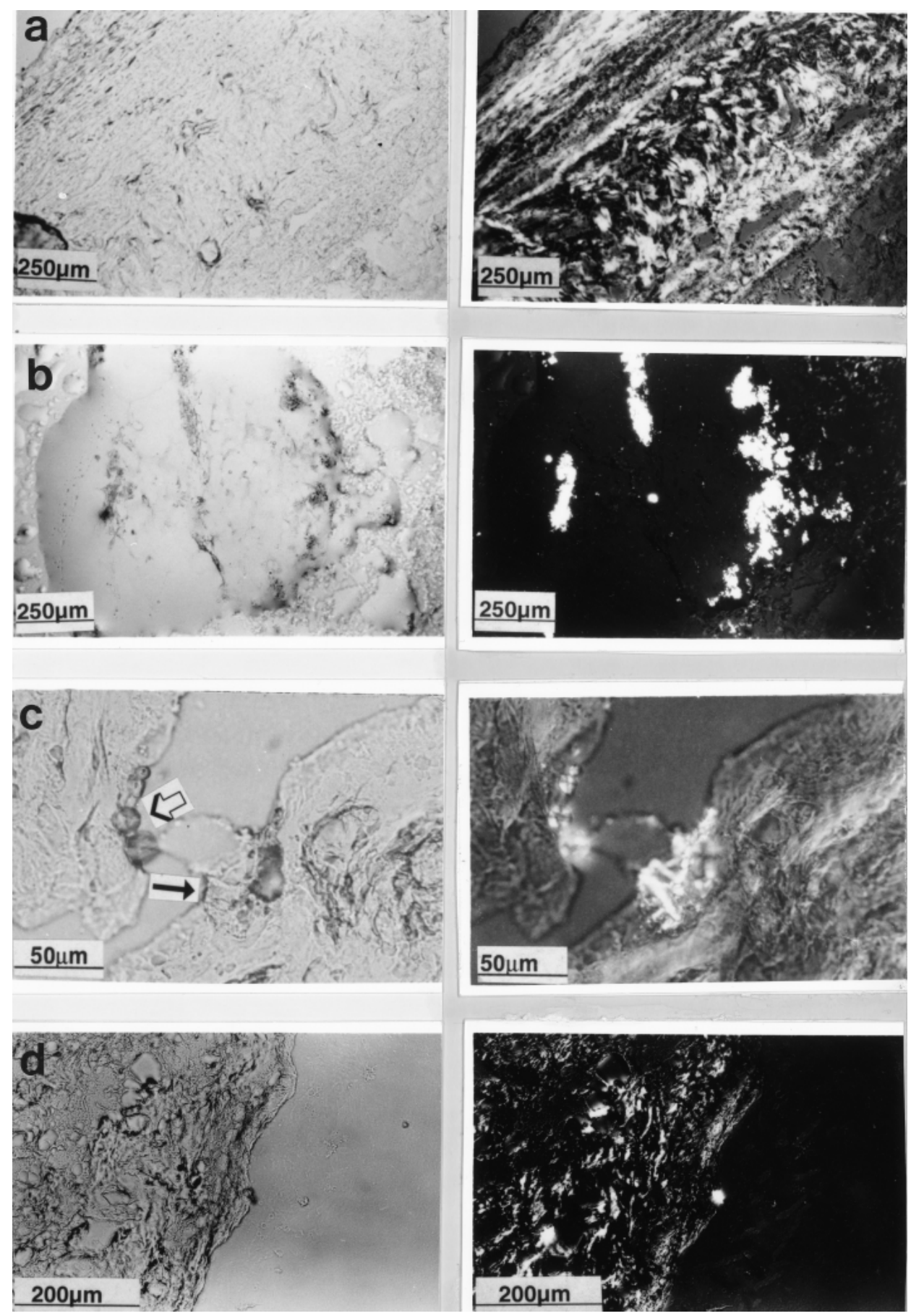

FIGURE 2. Pairs of photomicrographs of breast tissue in which the left photograph is shown in plane-polarized light, and the right one is the same field of view under crossed polarizers. See Table 1 for patient description. (a) Collagen (scar-like tissue) in capsular tissue surrounding silicone breast implant in patient no. 7. Section is $10 \mu \mathrm{m}$ thick. (b) Birefringent crystals of lipid (identified by Raman spectroscopy) in droplet of fat within $10 \mu \mathrm{m}$ thick section from reduction patient no. 1. Microscopy shows these features to be bundles of radiating needles, in which the tips of the needles are too thin to show birefringence. (c) At least two types of highly birefringent material in $20 \mu \mathrm{m}$ thick tissue section from implant patient no. 5. High-relief, round particles showing "Maltese cross" under crossed polarizers (hollow arrow) are starch. Low-relief "strands" (filled arrow) that are best seen under crossed polarizers probably are suture material. (d) Birefringent particles within and near the edge of $20 \mu \mathrm{m}$ thick section of collagen-rich tissue from implant patient no. 4. Compare left and right views to observe that some of the birefringent particles in this tissue section have very low optical relief; their presence is only apparent under crossed polarizers. Raman microprobe analysis of the prominent bright grain on the right edge of the tissue revealed only bands for silicone. However, the grain was very heat sensitive and showed patterns of white and dark bands under crossed polarizers, suggestive of suture fragments. 

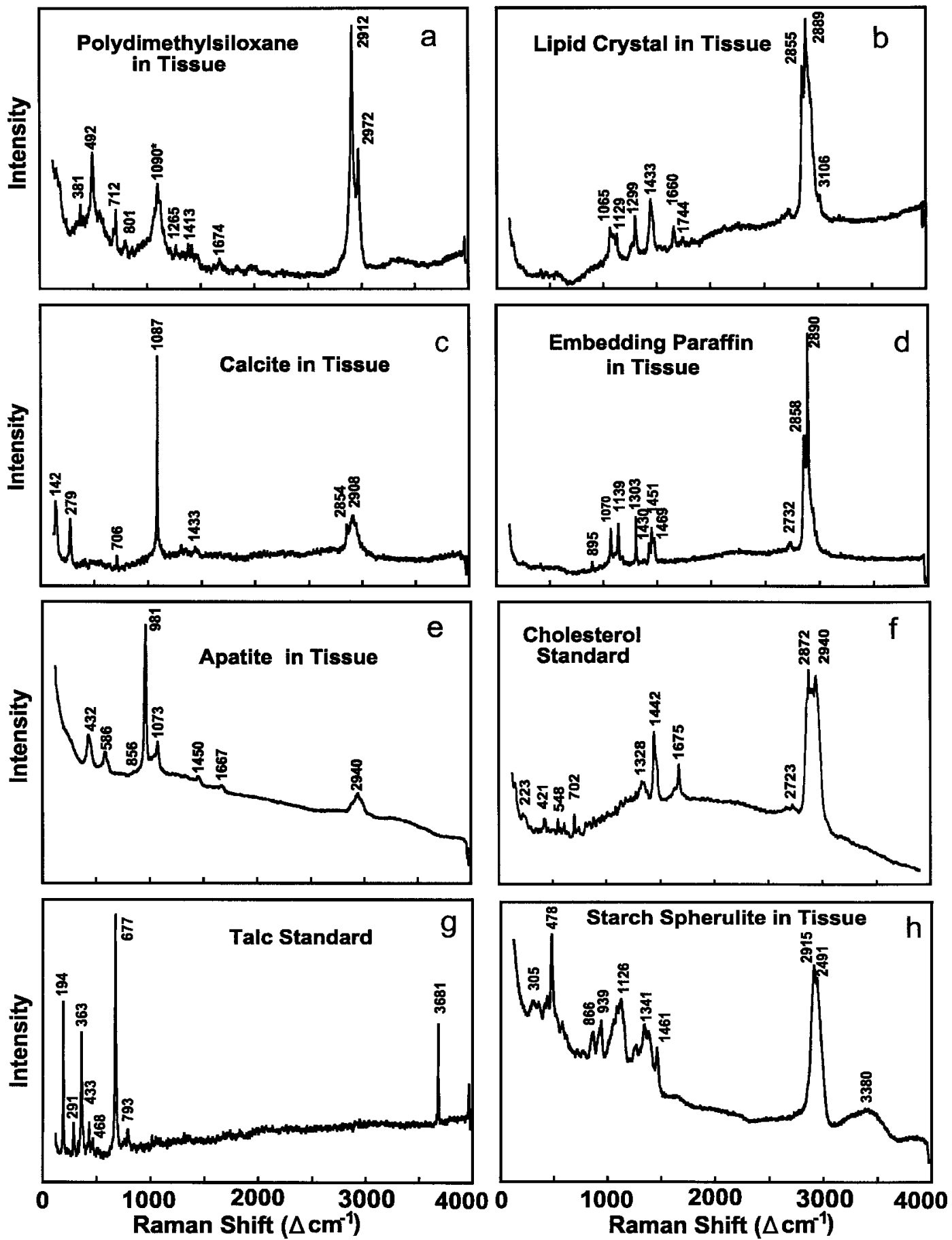

FigURE 3. Representative laser Raman microprobe analyses of microscopic regions in tissue and of laboratory standards, as noted. (a) Polydimethylsiloxane (PDMS, silicone) was detected only in the two implant patients whose implants had ruptured. The asterisk-marked band at $1090 \mathrm{~cm}^{-1}$ arises from the underlying glass microscope slide. (b) Spectrum of lipid crystals like those shown in Figure 2b. (c) Minute calcite grains were identified by Raman spectroscopy both in implant and reduction patients. (d) Paraffin was identified spectroscopically only in tissue from patient no. 9, our only sample that had been embedded previously in paraffin. (e) Apatite was identified spectroscopically in both implant and reduction patients. (f) Spectrum of certified-grade solid cholesterol from Fisher Scientific. (g) Spectrum of a flake of talc from a hand specimen from Tyrol, Austria. (h) Starch spherulites were identified spectroscopically in tissue from both implant and reduction patients. Some of the material was round and showed the typical Maltese cross under crossed polarizers, but other material was angular and showed more homogeneous extinction. 
patient (no. 9 in Table 1) whose implant period was 21 years. This material was chosen for study because of the macroscopic observation of solid, apparently crystalline material coating most of the capsule (pathologically described as capsular calcification). The Raman spectrum clearly identified this phase as apatite (Fig. 3e), but the specific solid-solution chemistry (presence and proportions of hydroxyapatite and carbonateapatite) could not be inferred (cf. Rolland et al. 1991). Despite their lack of observable birefringence, other apatite grains were distinguished due to their optical relief and subsequently identified spectroscopically in tissue sections from both explant and reduction patients.

The polymer silicone, in the form of either a gel or an elastomer, is structurally non-crystalline - and therefore outside of the realm of "mineralogy" as defined here. However, silicone is a material of extreme interest in these tissue sections and does represent the linking of a specific chemical composition with a specific structure, analogous to a mineral. Silicone is optically isotropic and has a refractive index of $\sim 1.4$ (exact index depends on degree of polymerization; Smith 1991), as compared to lipids with a refractive index of $\sim 1.46$. Fortunately, Raman spectroscopy provides species-specific structural analysis of a material and thus can be used to distinguish among all the Si-bearing compounds relevant to the silicone breast implant discussion (Fig. 4). Raman spectroscopy provided identification of silicone (compare Figs. 3a and 4e) in several fewmicrometer diameter regions in the capsular tissue from two patients (no. 4 and 5 in Table 1) whose implants had ruptured. Pathology reports of silicone, based solely on brightfield and/ or darkfield microscopy, typically describe the occurrence of silicone within obvious vacuoles. Our Raman analyses, in contrast, identified silicone in few-micrometer spaces between cells. One of the questions not answered in our present study is what accounts for the birefringence of some particle-like grains (Fig. 2d) whose Raman spectra showed silicone (Fig. 3a). One possibility is that these are fragments of siliconized suture material, a product developed to reduce friction during the emplacement of sutures.

In summary, our Raman analyses confirmed the occurrence of starch, apatite, calcite, and lipid (and, in some cases, associated $\beta$-carotene) in the tissue of both explant and reduction patients. We also identified silicone spectroscopically in an explant patient, and paraffin in the explant sample that had been embedded in paraffin and subsequently deparaffinized. The presence of suture fragments was inferred from their optical properties and heat sensitivity. We found no optical or Raman spectroscopic evidence for quartz or any other crystalline form of $\mathrm{SiO}_{2}$.

\section{DISCUSSION}

This study is just one example of how mineralogists can offer concrete, timely information on current "medical mineralogy" issues. In the case of silicone implants, on three different accounts - optical, spectroscopic, and geologic - the mineralogist can counter the assertions (Shanklin 1991; Shanklin and Smalley 1995; Shanklin and Smalley 1996a, 1996b, 1996c; Smalley and Shanklin 1997) that crystalline silica has formed in human tissue as a result of silicone medical implants that have released either amorphous silica (which subsequently transformed into crystalline silica) or silicone gel/elastomer (which underwent chemical reactions in the body that caused crystalline silica to precipitate).

From a geological perspective, the fact that, even after millions of years of residence on the ocean floor, the amorphous silica shells of diatoms remain non-crystalline (Shero 1994; Himmel et al. 1996) is very strong evidence against the suggested structural re-ordering of amorphous silica in the human body. Indeed, the types of silica dissolution and subsequent precipitation that are required to form quartz from amorphous silica would call for totally unreasonable variations in the $\mathrm{pH}$ of bodily fluids and unrealistic rates of recrystallization (Faure 1998). The pathology community can use these observations to help evaluate the probability that crystalline silica is forming in situ in the body and the types of conditions that would have to pertain for specific silica phases to precipitate.

Our combined optical and Raman spectroscopic study of breast tissue from nine patients spectroscopically identified silicone as the only Si-containing substance. Optical microscopy theory invalidates earlier pathology reports of "crystalline silica" as the "birefringent" phase observed in $5 \mu \mathrm{m}$ thin section of breast tissue, because these standard tissue sections are too thin to reveal the birefringence of quartz. In addition, it is very difficult to make a unique optical identification of any mineral in a grain whose largest dimension is only a few micrometers. Many of the observations of minute bright particles are due to simple light-scattering from particles in tissue and do not aid in their identification. The most birefringent particles that we did analyze proved to be calcite, which was detected both in patients who had breast reduction surgery and in patients who had a silicone breast implant removed.

The imprecise use of the term "birefringence" (for both true birefringence and light scattering from minute grains or microparticulate aggregates) causes both the discarding of information that is potentially useful (Chamot and Mason 1958) and the consideration of minerals that could not possibly be the unknown substance. The statement that "Silica is weakly birefringent (weaker than collagen), and exhibits a milky white appearance and irregular configuration..." (Craighead 1988, p. 715) unfortunately has caused misidentification of particles. The misconception that the "birefringence" of quartz or silica [sic] can be detected in $5 \mu \mathrm{m}$ thick samples can lead to the misidentification of an observably birefringent mineral as quartz. The incomplete discussion of the fact that fine-grained aggregates of (even amorphous) silica phases look milky white under crossed polarizers has caused investigators to regard milkiness as a distinct, diagnostic property of silica. Indeed, very fine-grained aggregates of crystalline calcite (high birefringence), quartz and apatite (low birefringence), fluorite (no birefringence), their amorphous analogs, and almost any transparent solid would produce a similar milkiness due to light scattering. Furthermore, even single individual transparent grains, regardless of whether they are inherently isotropic or birefringent, can appear bright under crossed polarizers due to light scattering off of their faces. This brightness occurs if there is a mismatch in the refractive indices of the particle and the enclosing medium, and it is enhanced for very irregularly shaped 
grains. Particularly pertinent to the pathology literature on silicone breast implants is the fact that minute bright grains (under crossed polarizers) or milky white clusters of particles need not be Si-bearing phases, but also could be microcrystalline apatite like the material that we and others (Rolland et al. 1991; Poggi et al. 1998) have identified by microchemical and microstructural analyses of mammary tissue samples. The distinction between various "brightness effects" under crossed polarizers is hampered because the typical pathology micro- scope is not outfitted with a rotating stage that would permit the differentiation between truly birefringent materials (which go extinct upon rotation of the stage) and light-scattering off of aggregates of randomly oriented minute grains (which remain hazy white regardless of sample orientation).

This blurring of the optical distinction between birefringence and light-scattering properties of a material may have led to the confusion in the literature about the structural difference between crystalline and amorphous forms of a compound. Such inappro-
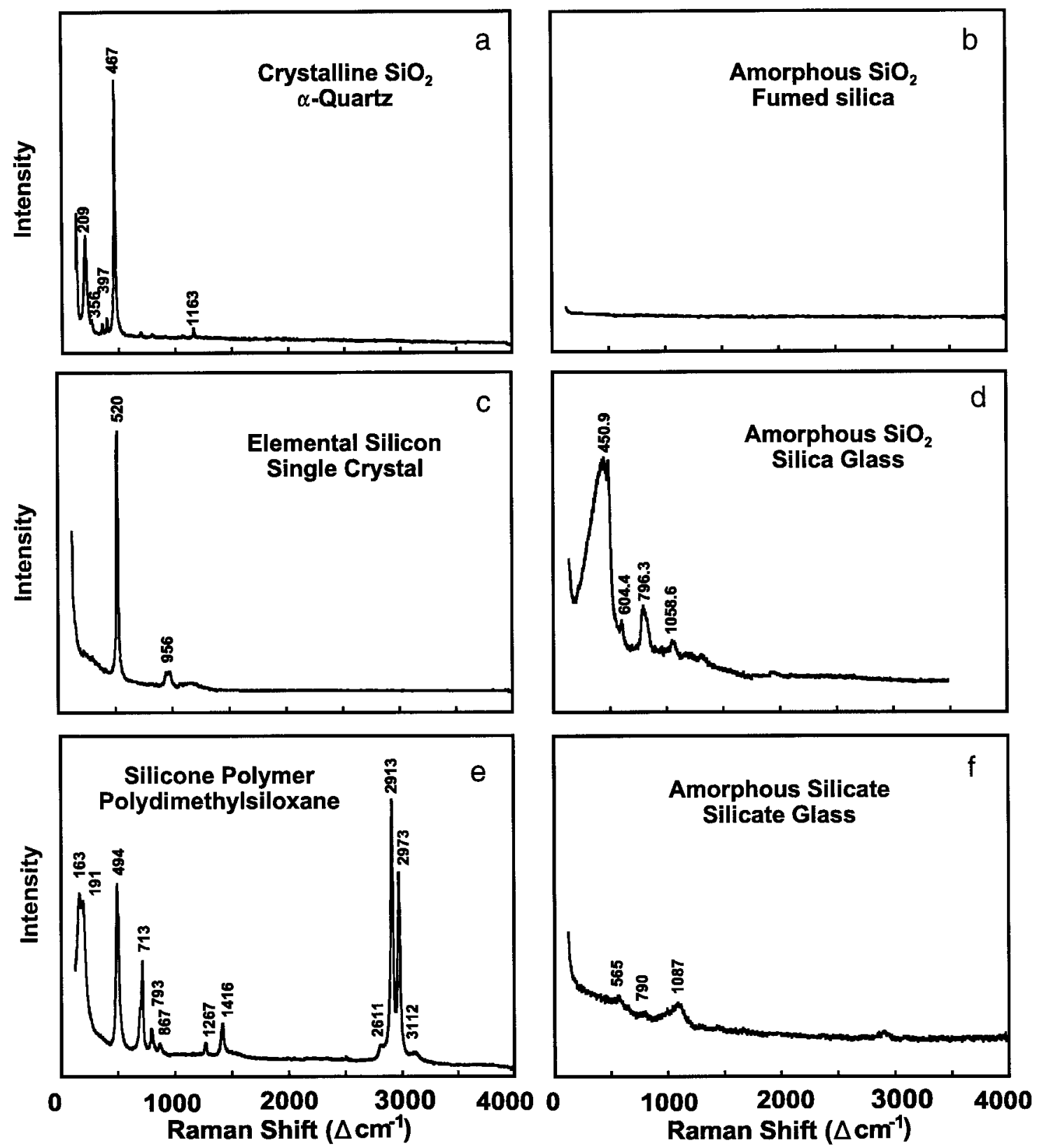

FIGURE 4. Raman spectra of Si-bearing standards. (a) Quartz from Hot Springs, Arkansas. (b) Amorphous fumed silica from Cabot Corporation, like that used to reinforce silicone elastomer shells of breast implants; extremely low-density "fluffy" material. (c) Polished elemental silicon wafer, (100) section. (d) So-called "fused quartz" tubing. (e) Silicone gel from Dow Corning, like that used to fill breast implants. (f) Silicate glass slide like that typically used for thin sections; compare to glass band in Figure 3a, which is scaled differently. 
priate terms as "pseudocrystalline" (Barker et al. 1978) and "partially polarizing" occur in the medical literature on silicone breast implants. However, due to the medical recognition that the state of crystallinity of inhaled silica particles may strongly affect lung response (Craighead 1988; Ross et al. 1993; Corn and Corn 1995), it is very important to use the most definitive, diagnostic optical criteria in examining the affected lung tissue.

Rheumatologists (Freemont and Denton 1991), the Silicosis and Silicate Disease Committee (Craighead 1988), and private analytical companies (McCrone et al. 1979; McCrone 1998) already have addressed many important issues of the optical characterization and identification of small particles. Much of the above work concerns the appearance of free-standing particles not embedded in tissue or embedded particles whose identity is assumed based on the medical context (patient's occupation, symptoms of disease). Table 2 represents information on birefringence and refractive index for phases pertinent to the pathology of breast tissue. The birefringence data indicate the "visibility" of larger grains under crossed polarizers (observation of real birefringence). The refractive index data indicate the strength of the optical relief of a mineral and how readily tiny particles would be seen as "bright" under crossed polarizers due to light scattering. Such compilations of optical constants of minerals can be of practical use to medical microscopists. In addition, they illustrate that substances with the same composition can have different properties (polymorphs calcite and aragonite; phases weddellite and whewellite, representing different degrees of hydration; quartz and fumed silica). These data also show that the specific chemistry of a mineral affects its properties, which is especially obvious in the cases of hydroxyapatite (reported by pathologists as "non-birefringent;" Surrat et al. 1991) and carbonate-apatite (recognized as birefringent in some dental studies; Wolman 1975), as well as the calcium oxalate phases weddellite (birefringence $=0.021$ ) and whewellite (birefringence $=0.160$; see Table 2).

The term "calcification" is used commonly in the medical literature to refer to hard, so-called mineralized materials in various parts of the body. The pathology of tissues associated with these "calcifications" frequently is studied as a means of identifying (pre-)cancerous conditions. In many instances, however, neither the specific chemistry (is calcium present?) nor structural state of the mineralization is documented (e.g., Woods et al. 1998), despite the multiple calcium phases possible. For instance, observed microcalcifications in breast tissue have been reported (Frappart et al. 1986; Fandos-Morera et al. 1988; Tornos et al. 1990; Surratt et al. 1991; Rolland et al. 1991; Mihaescu and Burri 1995) to consist of calcite, aragonite, weddellite (calcium oxalate dihydrate, $\mathrm{CaC}_{2} \mathrm{O}_{4} \cdot 2 \mathrm{H}_{2} \mathrm{O}$ ), whewellite (calcium oxalate monohydrate, $\mathrm{CaC}_{2} \mathrm{O}_{4} \cdot \mathrm{H}_{2} \mathrm{O}$ ), apatite, and calcium oxalate (structure and hydration state unspecified), but the supporting analyses are not uniformly convincing (see below). Physicians recognized that " $[t]$ he composition [oxalate vs. phosphate] of breast calcifications may give an idea as to their origin" (Fandos-Morera et al. 1988, p. 325) and that certain compositions may be more strongly associated with cancerous conditions (e.g., Fandos-Morera et al. 1988; Radi 1989; Frouge et al. 1993). Thus, the identification of the specific mineralogy of calcifications, e.g., which calcium phos- phate phase (members of the apatite group, brushite) and which of the calcium oxalate hydrates, provides further clues to the origin of the chemical components and the (bodily) conditions during precipitation.

Recent pathology research, using a variety of analytical techniques on materials in breast and other tissue, has had mixed success. The typical compositional means of distinguishing between calcium oxalate and calcium phosphate compounds in tissue sections, for instance, has been to observe whether energy-dispersive X-ray spectra show the presence of calcium and phosphorus, or calcium alone-without regard for the fact that calcium oxalate cannot be distinguished from calcium carbonate this way. Correlative electron microprobe analysis and optical microscopy have shown that the calcium phosphate precipitates in tissue do not appear birefringent, whereas calcium oxalate deposits do (see Table 2). However, in many cases, the reported hydration state of a calcium oxalate phase is not determined unequivocally, as through X-ray or electron diffraction patterns. Moreover, some phase equilibria studies (Deganello 1986; Lepage and Tawashi 1982; Tozuka et al. 1986) and optical microscopic descriptions raise the question of whether the hydration state of the calcium oxalate phase may be changed during the standard pathology processing and staining of the tissue section (note the large difference in birefringence between weddellite and whewellite; see Table 2).

The need to distinguish between a chemical element or component and the various compounds that contain it also arises in the analysis for silicone in the body. Although there are several analytical techniques that can identify and/or quantify the presence of silicone in human tissue and blood samples, some researchers have used the presence of elemental Si as a proxy in the analysis for silicone-without due consideration of the natural abundance of inorganic Si-containing compounds in the environment and in the human body (Barnard et al. 1997; Leung and Edmond 1997). As a consequence, it is impossible to draw definitive conclusions about silicone concentration based on data about Si (Sturrock 1998).

More (structurally) specific microanalytical techniques, e.g., electron microprobe analysis, SEM, TEM, FTIR, and Raman spectroscopy, are needed for the identification of particles in tissue section (cf. Marcus 1997). The individual techniques need to be evaluated for their limitations in the tasks at hand and selected for their directness in providing positive (structural and chemical) identification of the expected phases. Again, the silicone breast implant literature provides an example of the range of analytical techniques - each with its inherent limitations - that can be applied to characterize completely minute volumes of complex materials, including minerals (Silver et al. 1993; Čavič-Vlasak et al. 1996). The work of pathologists McDonald and Roggli (1995) is a good example of how optical visualization of particles in (lung) tissue can be followed by electron microprobe (SEM with EDAX) analyses. These authors detected the presence of only $\mathrm{Si}$ in some particles, and concluded that they most likely were an $\mathrm{SiO}_{2}$ phase. McDonald and Roggli (1995) also appropriately noted that undetected light elements could be present in the particles, and that X-ray emission spectra do not provide information on the polymorphic form or state of crystallinity of a substance. 
TABLE 2. Optical constants of some materials that reportedly do or possibly could occur in mammary tissue sections

\begin{tabular}{|c|c|c|c|c|}
\hline Material* & Refractive Indices & Birefringence & $\begin{array}{l}(\mu \mathrm{m}) \text { to see } \\
\text { birefringence }\end{array}$ & \\
\hline $\begin{array}{l}\text { alcite, } \neq \mathrm{CaCO}_{3} \\
\text { agonite, } \neq \mathrm{CaCO}_{3} \\
\text { droxyapatite, } \S \mathrm{Ca}_{5}\left(\mathrm{PO}_{4}\right)_{3} \mathrm{OH} \\
\text { arbonate-apatite, } £ \S \mathrm{Ca}_{5}\left(\mathrm{PO}_{4}, \mathrm{CO}_{3}\right)_{3}(\mathrm{OH}, \mathrm{F}) \\
\text { lartz, } \neq \mathrm{SiO}_{2} \\
\text { lc, } \neq \mathrm{Mg}_{3} \mathrm{Si}_{4} \mathrm{O}_{10}(\mathrm{OH})_{2} \\
\text { eddellite, } \S \mathrm{CaC}_{2} \mathrm{O}_{4} \cdot 2 \mathrm{H}_{2} \mathrm{O} \text { (calcium oxalate) } \\
\text { hewellite, } \S \mathrm{CaC}_{2} \mathrm{O}_{4} \cdot 1 \mathrm{H}_{2} \mathrm{O} \text { (calcium oxalate) } \\
\text { arch\|l } \\
\text { lk Suture\|l } \\
\text { cril Suture }\end{array}$ & $\begin{array}{l}58 ; \varepsilon=1.486 \\
30 ; \beta=1.680 ; \gamma=1.685 \\
51 ; \varepsilon=1.644 \\
03,1.628 ; \varepsilon=1.598,1.619 \\
44 ; \varepsilon=1.553 \\
44 ; \beta \sim 1.59 ; \gamma \sim 1.59 \\
23 ; \varepsilon=1.544 \\
89 ; \beta=1.553 ; \gamma=1.649 \\
3 \\
4 ; \varepsilon=1.59\end{array}$ & $\begin{array}{c}0.172 \\
0.155 \\
0.007 \\
0.005 \text { to } 0.013 \neq \\
0.009 \\
\sim 0.05 \\
0.021 \\
0.160 \\
\text { igh, unknown bir } \\
0.04 \\
\text { birefringent } \\
0 \text { (isotropic) } \\
0 \text { (isotropic) } \\
0 \text { (isotropic) } \\
0 \text { (isotropic) }\end{array}$ & $\begin{array}{c}0.6 \\
0.7 \\
14.3 \\
20.0 \text { to } 7.7 \\
11.1 \\
2.0 \\
4.8 \\
0.6 \\
\text { very small } \\
2.5 \\
\text { nall, unknowr } \\
\text { n/a } \\
\text { n/a } \\
\text { n/a } \\
\text { n/a }\end{array}$ & $\begin{array}{c}\text { YES } \\
\text { YES } \\
\text { NO } \\
\text { NO to MAYBE } \\
\text { NO } \\
\text { YES } \\
\text { WEAK } \\
\text { YES } \\
\text { YES } \\
\text { YES } \\
\text { YES } \\
\text { NO } \\
\text { NO } \\
\text { NO } \\
\text { NO }\end{array}$ \\
\hline \multicolumn{5}{|c|}{$\begin{array}{l}\text { Note: Crystalline materials such as calcite, weddellite, and apatite have been identified in breast tissue in so-called "micro-calcifications" (Frappart et al. } \\
\text { 1986; Fandos-Morera et al. 1988; Mihaescu and Burri 1995). Silicates such as talc and carbohydrates such as starch, are common in powders used in } \\
\text { surgical gloves (Kasper and Chandler 1994). Also after surgery, there is the possibility of finding residual suture material in the tissue, e.g., Vycril. } \\
\text { * Symbols next to substance names are keyed to reference sources for the listed refractive index and birefringence values. } \\
\text { † Visibility under crossed polarizers (assuming that } 100 \mathrm{~nm} \text { retardation is required to observe brightness). See column } 4 \text { for minimum grain thick- } \\
\text { nesses (in micrometers) required to see brightness (i.e., observe inherent birefringence). } \\
\text { † Deer et al. } 1992 \text {. } \\
\text { \$ Roberts et al. } 1974 . \\
\text { |l Lange et al. } 1946 . \\
\text { \# Michael and Ferch } 1993 \text {. } \\
\text { * Smith 1991. Refractive index depends on degree of polymerization, etc. }\end{array}$} \\
\hline
\end{tabular}

Raman microprobe spectroscopy has proven to be a very useful adjunct to the optical microscopy of foreign materials in tissue sections. The Raman spectra of the important phases of interest in the silicone breast implant and silicosis debates (Figs. 3 and 4) are unique and readily distinguished from each other. Submicrometer particles of amorphous silica and even severalmicrometer aggregates of the low-density fumed silica that is incorporated into silicone elastomer shells, however, provide too low of a concentration within the laser irradiation volume to produce a definitive Raman spectrum (see Fig. 4b). The identification of submicroscopic particles of amorphous silica in tissue sections, however, is an analytical challenge that would be handled appropriately by SEM and TEM techniques (cf. Poggi et al. 1998).

Spectroscopic evidence of crystalline silica in breast tissue is lacking from our very limited analyses. Our combined optical microscopic and Raman spectroscopic study instead suggests that observed, truly birefringent phases in breast tissue are much more likely to be calcite and paraffin. The pathology literature further supports the possibility of the moderately birefringent form of calcium oxalate known as weddellite or its highly birefringent, less hydrous counterpart, whewellite (see Table 2, this work; Frappart et al. 1984; Fandos-Morera et al. 1988; Tornos et al. 1990; Surratt et al. 1991; Mihaescu and Burri 1995).

This study clearly is not a definitive investigation of all the materials that occur in the breast tissue of patients who had silicone breast implants. For instance, we did not address the possible presence of amorphous silica in our tissue sections. A more definitive investigation would require a statistically significant number of well-documented tissue samples that were studied using several microanalytical techniques in collaboration with a pathologist who was well versed in the medical issues. The current study, however, highlights the need for discussions between pathologists and mineralogists to optimize the techniques used in sample-handling, section-preparation, and materials analysis.

\section{ACKNOWLEDGMENTS}

This research was supported in part by an unrestricted gift from the Dow Corning Corporation. We thank H. Catherine Skinner, Jonathan Stebbins (associate editor), and an anonymous reviewer for their helpful comments on an earlier version of the manuscript. We also thank Diane Toeniskoetter for preparation of the tissue sections.

\section{REFERENCES CITED}

Barker, D.E., Retsky, M.I., and Schultz, S. (1978) "Bleeding" of silicone from baggel breast implants, and its clinical relation to fibrous capsule reaction. Plastic and Reconstructive Surgery, 61, 836-841.

Barnard, J.J., Todd, E.L., Wilson, W.G., Mielcarek, R., and Rohrich, R.J. (1997) Distribution of organosilicon polymers in augmentation mammaplasties at autopsy. Plastic and Reconstructive Surgery, 100, 197-203.

Beckett, W. (chairman) (1997) Adverse effects of crystalline silica exposure. Report of the American Thoracic Society. American Journal of Respiratory and Critical Care Medicine, 155, 761-765.

BéruBé, K., Mossman, B., Quinlan, T., and Taatjes, D. (1998) Diverse microscopy imaging techniques for studies of asbestos-induced lung disease. The Americas Microscopy and Analysis, March 1998, 15-17.

Čavič-Vlasak, B.A., Thompson, M., and Smith, D.C. (1996) Silicones and their determination in biological matrices. Analyst, 121, 53R-63R.

Chamot, E.M. and Mason, C.W. (1958) Handbook of chemical microscopy, volume $1,3^{\text {rd }}$ edition, 502 p. Wiley, New York.

Corn, J.K. and Corn, M., Eds. (1995) Proceedings of the International Conference on Crystalline Silica Health Effects: Current state of the art. Applied Occupational and Environmental Hygiene, 10, 977-1156.

Craighead, J.E. (chairman) (1988) Diseases associated with exposure to silica and nonfibrous silicate minerals. Report of the Silicosis and Silicate Disease Committee. Archives of Pathology and Laboratory Medicine, 112, 673-720.

Deer, W.A., Howie, R.A., and Zussman, J. (1992) An introduction to the rock-forming minerals, 696 p. Longman Group U.K. Limited, Essex, England.

Deganello, S. (1986) Phase transitions of calcium oxalate trihydrate and epitaxy in the weddellite-whewellite system. Scanning Electron Microscopy, 1986, 17211728.

Fandos-Morera, A., Prats-Esteve, M., Tura-Soteras, J.M., and Traveria-Cros, A. (1988) Breast tumors: composition of microcalcifications. Radiology, 169, 325-327. 
Faure, G. (1998) Principles and applications of geochemistry, $2^{\text {nd }}$ edition, 124-127. Prentice Hall, Upper Saddle River, New Jersey.

Frappart, L., Remy, I., Lin, H.C., Bremond, A., Raudrant, D., Grousson, B., and Vauzelle, J.L. (1986) Different types of microcalcifications observed in breast pathology. Virchows Archiv A, 410, 179-187.

Freemont A.J. and Denton, J. (1991) Atlas of synovial fluid cytopathology, $140 \mathrm{p}$. Kluwer, Boston.

Frouge, C., Meunier, M., Guinebretiére, J.M., Gilles, R., Vanel, D., Contesso, G., Di Paola, R., and Blery, M. (1993) Polyhedral microcalcifications at mammography: Histologic correlation with calcium oxalate. Radiology, 186, 681-684.

Goldsmith, D.F. (1994) Health effects of silica dust exposure. In Mineralogical Society of America Reviews in Mineralogy, 29, 545-606.

Guthrie, G.D. (1992) Biological effects of inhaled minerals. American Mineralogist, 77, 225-243.

Guthrie, G.D. and Mossman, B.T., Eds. (1993) Health effects of mineral dusts. In Mineralogical Society of America Reviews in Mineralogy, 28, $584 \mathrm{p}$.

Hardy, T.S. and Weill, H. (1995) Crystalline silica: Risks and Policy. Environmental Health Perspectives, 103, 152-155.

Himmel, B., Fiedler, O., Bech, H., and Bulow, W. (1996) Analysis of carbonic diatomite sediments from northern Germany. Chemie der Erde, 56, 392-397.

Iler, R.K. (1979) The chemistry of silica: Solubility, polymerization, colloid and surface properties, and biochemistry, $866 \mathrm{p}$. Wiley, New York

Kasper, C. (1994) Histologic features of breast capsules reflect surface configuration and composition of silicone bag implants. American Journal of Clinical Pathology, 102, 655-659.

Kasper, C. and Chandler, P.J. (1994) Talc deposition in skin and tissues surrounding silicone gel-containing prosthetic devices. Archives of Dermatology, 130, 48-53.

Lange, N.A., Forker, G.F., and Burington, R.S., Eds. (1946) Lange's handbook of chemistry, p. 1028. Handbook Publishers, Inc., Sandusky, Ohio.

Lepage, L. and Tawashi, R. (1982) Growth and characterization of calcium oxalate dihydrate crystals (weddellite). Journal of Pharmacology Science, 71, 10591062 .

Leung, F.Y. and Edmond, P. (1997) Determination of silicon in serum and tissue by electrothermal atomic absorption spectrometry. Clinical Biochemistry, 30, 399403 .

Marcus, D.M. (1997) Analytical review of the scientific literature on silicone immune responses: comment on an article by Marcus-reply. Arthritis and Rheumatism, 40, 1731.

McCrone, W.C. (1998) Particle analysis. Microscopy Today, 98, June/July 1998, $18-19$.

McCrone, W.C., Delly, J.G., Palenik, S. J. (1979) The particle atlas, volume V: Light microscopy atlas and techniques, p. 1145-1454. Ann Arbor Science Publishers, Inc., Michigan.

McDonald, J.W. and Roggli, V.L. (1995) Detection of silica particles in lung tissue by polarizing light microscopy. Archives of Pathology and Laboratory Medicine, 119, 242-246.

Michael, G. and Ferch, H. (1993) Basic characteristics and applications of AEROSIL, Technical Bulletin Pigments, Number 11, 81 p. Applied Technology, Inorganic Chemical Products Division, Degussa AG, Frankfurt am Main, Germany.

Mihaescu, A. and Burri, G. (1995) Calcium oxalate crystals in benign breast cyst fluid. Diagnostic Cytopathology, 12, 67-70.

Murphy, S.A., BéruBé, K.A., Pooley, F.D., and Richards, R.J. (1998) The response of lung epithelium to well characterised fine particles. Life Sciences, 62, 17891799.

Noone, R.B. (1997) A review of the possible health implications of silicone breast implants. Cancer, 79, 1747-1756.

Pasteris, J.D. and Chou, I-M. (1998) Fluid-deposited graphitic inclusions in quartz: Comparison between KTB (German Continental Deep-Drilling) core samples and artificially re-equilibrated natural inclusions. Geochimica et Cosmochimica Acta, 62, 109-122.

Peters, W. (1995) Silicone breast implants and autoimmune connective tissue disease. Annals of Plastic Surgery, 34, 103-109.

Picard, F., Alikacem, N., Guidoin, R., and Auger, M. (1997) Multinuclear solidstate NMR spectroscopy of envelopes from virgin and explanted silicone breas prostheses: An exploratory study. Magnetic Resonance Medicine, 37, 11-17.

Poggi, S.H., Skinner, H.C.W., Ague, J.J., and Carter, D. (1998) Using scanning electron microscopy to study mineral deposits in breast tissues. American Mineralogist, $83,1122-1126$

Radi, M.J. (1989) Calcium oxalate crystals in breast biopsies. An overlooked form of microcalcification associated with benign breast disease. Archives of Pathology and Laboratory Medicine, 113, 1367-1369.

Raso, D.S. and Greene, W.B. (1997) Silicone breast implants: pathology. Ultrastructural Pathology, 21, 263-71.
Raso, D.S., Greene, W.B., Vesley, J.J., and Willingham, M.C. (1994) Light microscopy techniques for the demonstration of silicone gel. Archives of Pathology and Laboratory Medicine, 118, 984-987.

Roberts, W.L., Rapp, G.R., and Weber, J. (1974) Encyclopedia of minerals, 664 p. Van Nostrand Reinhold, New York.

Rochow, E.G. (1987) Silicon and silicones, 180 p. Springer-Verlag, New York.

Rolland, C., Guidoin, R., Ledoux, R., Zerguini, A., and Roy, P.E. (1991) Carbonatehydroxyapatite, hopeite, and parascholzite in fibrous capsules surrounding silicone breast implants. Canadian Mineralogist, 29, 337-345.

Ross, M., Nolan, R.P., Langer, A.M., and Cooper, W.C. (1993) Health effects of mineral dusts other than asbestos. In Mineralogical Society of America Reviews in Mineralogy, 28, 361-407.

Shanklin, D.R. (1991) Late tissue reactions to silicone and silica: The natural history of silicone-associated diseases with special reference to infections and immunological markers in tissue. In M.E. Stratmeyer, Ed. Silicone in medical devices, FDA no. 92-4249, 103-125. HHS Publications, Food and Drug Administration, Washington, D.C.

Shanklin, D.R. and Smalley, D.L. (1995) Microscopic techniques and histologic findings in silicone mammary implant capsules and regional paranodal tissues. In Abstracts of the Immunology of Silicones Workshop, 13-14 March 1995, Bethesda, MD. National Institutes of Health.

- (1996a) Microscopic techniques and histologic findings in silicone mammary implant capsules and regional paranodal tissues. In M. Potter and N.R. Rose, Eds., Immunology of silicones, p. 253-268. Springer Verlag, Berlin. (1996b) Silicone immunology. Science and Medicine, Sept/Oct 1996, 22-31. - (1996c) Evidence for degradation of silicones in vivo with recrystallization as silica in peripheral nerve. In Experimental Biology, 96, 14-17 April 1996, Washington, D.C. The FASEB Journal-Abstracts 1996, 10(3), A785.

Shero, B.R. (1994) Diatom assemblages of the past 11,000 years from the Yellowstone Lake Basin, Wyoming, USA. In J.P. Kocielek, Ed., Proceedings of the $11^{\text {th }}$ International Diatom Symposium, San Francisco, 1990, 549-555. California Academy of Sciences, Memoir 17, San Francisco.

Silver, R.M., Sahn, E.E., Allen, J.A., Sahn, S., Greene, W., Maize, J.C., and Garen, P.D. (1993) Demonstration of silicon in sites of connective-tissue disease in patients with silicone-gel breast implants. Archives of Dermatology, 129, 63-68.

Skinner, H.C.W., Ross, M., and Frondel, C. (1988) Asbestos and other fibrous minerals: Mineralogy, crystal chemistry and health effects, 204 p. Oxford University Press, New York.

Smalley, D.L. and Shanklin, D.R. (1997) Analytic review of the scientific literature on silicone immune responses: Comment on the article by Marcus. Arthritis and Rheumatism, 40, 1730.

Smith, A.L., Ed. (1991) The analytical chemistry of silicones, 551 p. Wiley, New York.

Sturrock, R.D. (chairman) (1998) Silicone Gel Breast Implants: The Report of the Independent Review Group, 36 p. Jill Rogers Associates, Cambridge, U.K.

Surratt, J.T., Monsees, B.S., and Mazoujian, G. (1991) Calcium oxalate microcalcification in the breast. Radiology, 181, 141-142.

Tornos, C., Silva, E., El-Naggar, A., and Pritzker, K.P. (1990) Calcium oxalate crystals in breast biopsies. The missing microcalcifications. American Journal of Surgical Pathology, 14, 961-968.

Tozuka, K., Moriguchi, H., Hara, Y., Yonese, Y., Abe, H., and Konjiki, T. (1986) Study of the transformation of weddellite to whewellite in calcium oxalate stones by x-ray diffraction 32, 1093-1097 (in Japanese).

Vondráček, P. and Doležel, B. (1984) Biostability of medical elastomers: A review. Biomaterials, 5, 209-214.

Werner, A.J., Hochella, M.F., Guthrie, G.D., Hardy, J.A., Aust, A.E., and Rimstidt, J.D. (1995) Asbestiform riebeckite (crocidolite) dissolution in the presence of Fe chelators: Implications for mineral-induced disease. American Mineralogist, 80, 1093-1103.

Wolman, M. (1970) On the use of polarized light in pathology. Pathology Annual, 5, 381-416.

(1975) Polarized light microscopy as a tool of diagnostic pathology. Journal of Histochemistry and Cytochemistry, 23, 21-50.

Wolman, M. and Kasten, F.H. (1986) Polarized light microscopy in the study of the molecular structure of collagen and reticulin. Histochemistry, 83, 41-49.

Woods, J.E., Soh, S., and Wheller, T.M. (1998) Distribution and significance of microcalcifications in the neoplastic and nonneoplastic prostate. Archives of Pathology and Laboratory Medicine, 122, 152-155.

MANUSCRIPT RECEIVED JULY 27, 1998

MANUSCRIPT ACCEPTED JANUARY 21, 1999

PAPER HANDLED By JoNATHAN F. STEBbins 